\title{
Highly Efficient MCM-48-based Template Synthesis of Osmium and Platinum 3-D Nanonetworks
}

\author{
Chang Hoon Lee, Kwangyeol Lee, ${ }^{\star}$ Sukbok Chang, ${ }^{\dagger}$ Joon T. Park. and Bongsoo Kim ${ }^{\dagger .}$ \\ Department of Chemistry and Center for Electro- and Photo-Responsive Molecules, Korea University, \\ Seonl 136-701, Korea. "E-mail: kylee1@korea.ac.kr. \\ "Department of Chemistry and School of Molecular Science (BK 21), Korea Advanced Institute of Science and Technolog, \\ Daejeon 305-701, Korea. "E-mail: bongsoo@kaistackr. \\ Received October 4, 2005
}

Key Words : Mesoporous, Nanostructure, Template, IIeterogeneous, Catalysis

Nanostructured materials have attracted a great attention because of their novel size- and shape-dependent electronic, magnetic, optical, and catalytic properties that differ drastically from those of bulk materials.' Metals of nanosize, in particular, are expected to find useful applications in catalysis due to high surface area, ${ }^{2}$ and some results using nanoparticles as catalysts were reported. Ni/Pd core/shell nanoparticles show good catalytic activities in Sonogashira coupling reactions, ${ }^{3}$ and $\mathrm{Pd}$ nanoparticles with chiral ligands are good catalysts for asymmetric catalyses. ${ }^{4}$ These nanoparticles contain ligands on their surface, thus possessing very good solubilities in organic solvents. The improved solubility of nanoparticles, however, can impede facile recovery of the catalysts after reaction. Hyeon $e$ t al reported the preparation of micron-sized hollow palladium spheres composed of bare nanoparticles without surfactants and these materials showed excellent catalytic activities in Suzuki cross coupling reactions and a good recoverability, ${ }^{5}$ thus calling for further extensive studies on designed 3-D nanostructures of other metals for efficient catalyses and facile catalyst recovery processes.

Nanomaterials with smaller dimensions $(2-10 \mathrm{~nm}$ in diameter) $)^{\text {It.1c. } 6}$ could be obtained through template synthesis using mesoporous silicates ${ }^{7}$ such as SBA-15, MCM-41, and MCM-48. ${ }^{8-10}$ Metal precursors, however, do not readily diffuse into the small pore channels of these mesoporous silicates, and thus efficient methods to load the metal inside the pores need to be developed to prepare porous templatebased nanomaterials. Although the insertion of the metal precursors by solution-phase infiltration ${ }^{8}$ and thermal vapor infiltration? techniques have been successful in the preparation of nanostructured materials, the incorporated metal contents are rather low (3-10 wt \% of metal loading based on $\mathrm{SiO}_{2}$ template). Supercritical fluids with large diffusion coefficients and low viscosity have also been employed to increase the amount of precursors loaded into small mesopores. ${ }^{10}$ The required harsh conditions to generate supercritical fluids, however, are very cumbersome. Herein we report a facile preparation of 3-D structured $\mathrm{Os}$ and $\mathrm{Pt}$ nanonetworks by utilizing the capillary action of mesopores of MCM-48 toward molten organometallic precursors. Some preliminary results of the work described herein have been previously reported."

A Pyrex glass ampoule $(1 \times 5 \mathrm{~cm}$, wall thickness $=2 \mathrm{~mm})$ containing $\mathrm{C}_{16}-\mathrm{MCM}-48(0.2 \mathrm{~g})^{12}$ and $\mathrm{O}_{3}(\mathrm{CO})_{12}(0.75 \mathrm{~g} ; \mathrm{Os}$ metal content $=0.47 \mathrm{~g}$ ) is evacuated by a diffusion pump for $1 \mathrm{~h}$, and then flame-sealed. The ampoule is heated at $265^{\circ} \mathrm{C}$ in a silicone oil bath. The color change of MCM- 48 from white to brown indicates efficient sorption of brown liquid produced by the melting of thermolysis products of $\mathrm{O}_{3}(\mathrm{CO})_{12}$, such as $\mathrm{O}_{5} \mathrm{C}(\mathrm{CO})_{15}, \mathrm{O}_{6}(\mathrm{CO})_{18}$, and $\mathrm{O}_{7}(\mathrm{CO})_{21} .^{13}$ In order to induce decomposition of the Os cluster compounds into Os metal, the ampoule is heated at $265^{\circ} \mathrm{C}$ for 3 days, further heated at $350^{\circ} \mathrm{C}$ for $6 \mathrm{~h}$, and finally maintained at $400{ }^{\circ} \mathrm{C}$ for $24 \mathrm{~h}$. The black-colored powder thus obtained after ampoule breakage has been treated by $\mathrm{H}_{2}$ $(100 \mathrm{~mL} / \mathrm{min})$ at $400^{\circ} \mathrm{C}$ for $6 \mathrm{~h}$, which results in complete removal of the carbon contents (Elemental Analysis; C, $0.0 \%$ ). After subsequent thermal annealing of the black powder at $500{ }^{\circ} \mathrm{C}$ under $\mathrm{Ar}$ for $12 \mathrm{~h}$, the fumace is cooled down to room temperature, and the Os@MCM-48 sample is exposed to air. In order to obtain template-free Os nanomaterial, the resulting black powder is reacted with $48 \% \mathrm{HF}$ in $\mathrm{H}_{2} \mathrm{O}$ (20 molar excess based on $\mathrm{Si}$ content) at room temperature. Centrifugation and drying under vacuum give voluminous black powder $(0.51 \mathrm{~g})$. Figure 1 shows the Xray powder diffraction (XRD) patterns of (a) MCM-48, (b) Os $\left(9 \mathrm{MCM}-48\right.$ after thermal annealing at $500{ }^{\circ} \mathrm{C}$, (c) template-free Os nanomaterial. Figure 1d and 1e are the $\mathrm{XRD}$ patterns of $\mathrm{Pt}$ nanomaterials, which will be discussed later. The free MCM-48 template with a highly ordered structure exhibits a diffraction peak at $2 \theta=2.22^{\circ}$, which corresponds to (211) reflection (Fig. 1a). Figure 1b shows that the (211) peak is shifted to $2 \theta=2.25^{\circ}$ after Os impregnation, which suggests that some degree of lattice contraction of the original MCM-48 framework has been induced. The intensity of this peak is decreased to less than $20 \%$ of that of free MCM-48. Such a drastic decrease in the intensity of the diffraction peak due to silica framework indicates that large amount of $O s$ has been loaded inside the pores. ${ }^{14}$ Similar lattice contraction and intensity loss of XRD peak for material-filled mesoporous silicates has been previously observed. ${ }^{8.9 .10 k .15}$

$\mathrm{XRD}$ analysis (Fig. 1c) of the nanostructured Os network 


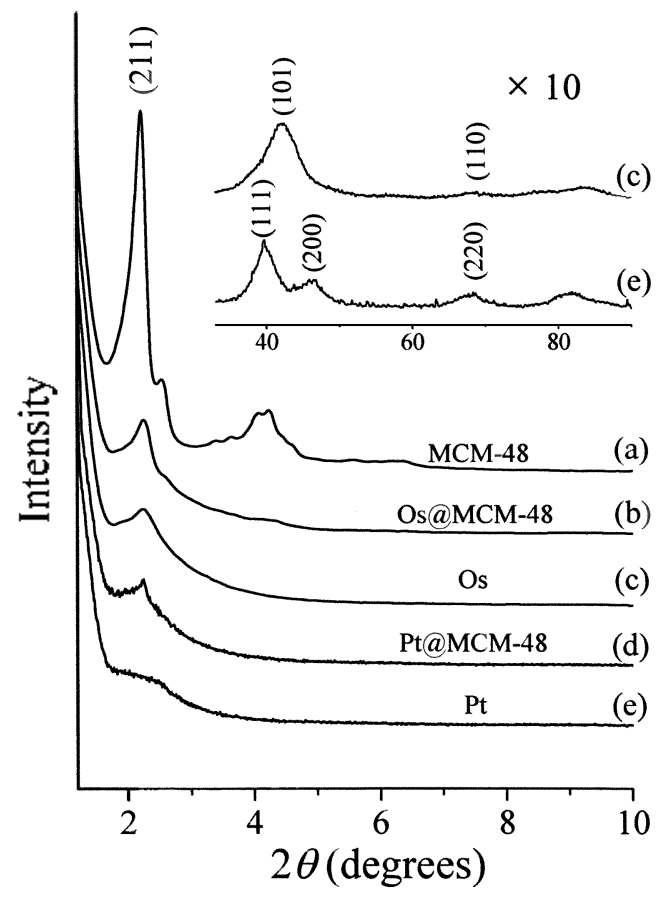

Figure 1. Changes in XRD patterns: (a) MCM-48, (b) Os (do) MCM48 after thermal annealings at $500^{\circ} \mathrm{C}$, (c) template-liree $\mathrm{Os}$, (d) Pl(o)MCM-48 afier thermal annealing at. $500^{\circ} \mathrm{C}$, and (e) lemplatefrec $\mathrm{Pt}$.

$(N-O s)$ shows an identical pattern to that of MCM-48 supported Os metal. The XRD pattern of the $N$-Os shows broad peaks at $43.6^{\circ}$ and $68.6^{\circ}$, which correspond to (101) and (110) reflections of hexagonally close-packed (hep) Os (JCPDS card No: 06-0662), respectively, as shown in the insel of Figure lc. Sharp XRD peaks at high angles are not observed, indicating that large Os particles are not formed on the outer surface of MCM-48. Figure 1e shows a rather broad peak around $20=2.2^{\circ}$, which is similar to that of MCM-48 template, and suggests that some degrec of longrange order transferred from the MCM-48 host still remains. Such a long-range ordered structure is further supported by transmission electron microscope (TEM) images. The TEM images of the template-free Os nanomaterial (Fig. 2a-c) show that it is composed of $O \mathrm{~s}$ particles with $50-500 \mathrm{~nm}$ diameter. These particles have a substructure in which nanoparticles with $-3 \mathrm{~nm}$ diameter are regularly networked, with textures similar to those of silica-based MCM-48. Figure $2 \mathrm{~d}$ shows that the $\mathrm{Os}$ nanoparticle aggregates are randomly dispersed, when they are not themally annealed within MCM-48. Obviously, the final annealing process at $500^{\circ} \mathrm{C}$ is an indispensable step for the nano-sized metal within the pore channels of MCM-48 to establish a longrange order. The mobility of molten nanoparticles within the pore channels at $500^{\circ} \mathrm{C}$ may explain the facile annealing process at this temperature. A dramatic lowering of melting point for nanowires of noble metals has been previously reported. $8:$ sh

In order to confirm that the facile metal impregnation is in fact due to the capillary action of MCM-48, nanostructured $\mathrm{Pt}$ has been prepared from an organometallic precursor

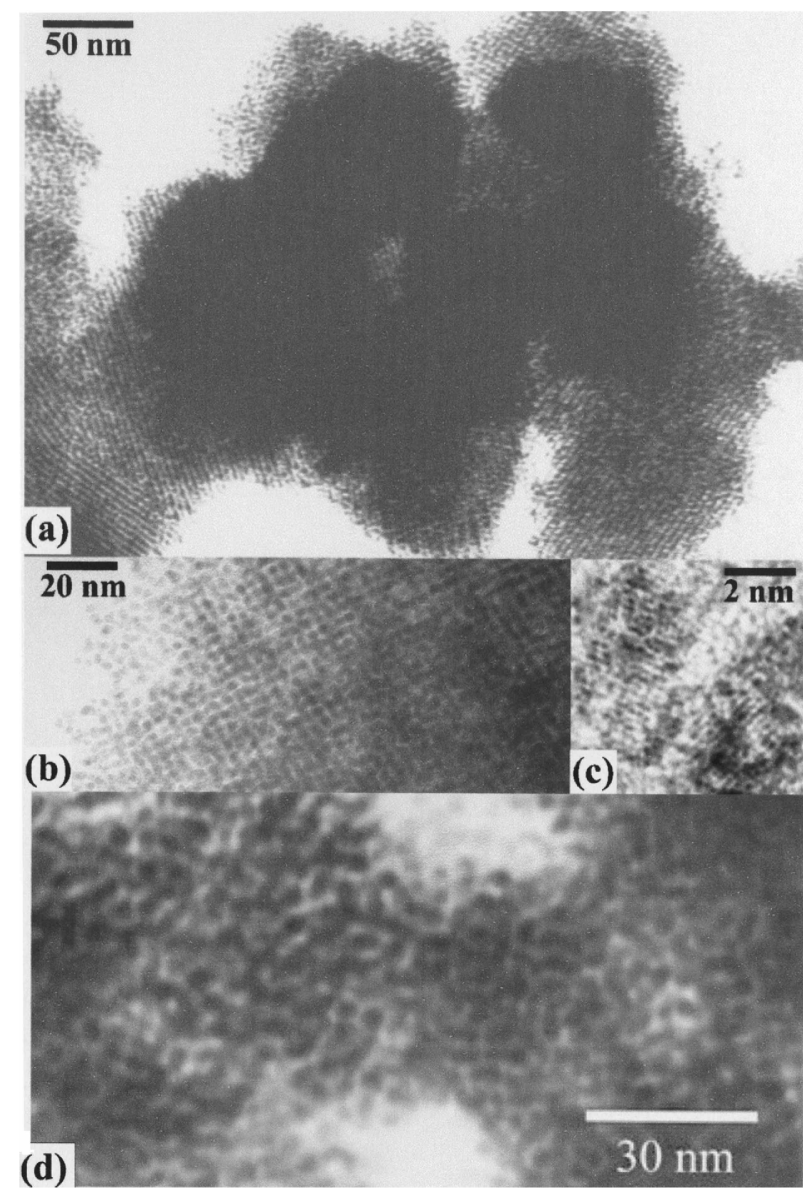

Figure 2. TI:M images of template-free nanostructured $O s$ : (a-c) al various magnifications after themal annealing at $500^{\circ} \mathrm{C}$, and (d) before thermal annealing at $500^{\circ} \mathrm{C}$.

$\mathrm{Pt}(\mathrm{COD}) \mathrm{Cl}_{2}$, of which the decomposition behavior is very different from $\mathrm{Os}_{3}(\mathrm{CO})_{12}$. While $\mathrm{Os}_{3}\left(\mathrm{CO}_{12}\right.$ slowly transforms to various long-lived viscous cluster compounds before decomposing to $\mathrm{Os}$ metal, $\mathrm{Pt}(\mathrm{COD}) \mathrm{Cl}_{2}$ decomposes directly to $\mathrm{Pt}$ upon melting (m.p. $-250^{\circ} \mathrm{C}$ ). If the sorption of the molten precursor due to the capillary action is not very efficient, large Pt particles will form only on the outer surface of MCM-48. When $\mathrm{Pt}(\mathrm{CO}))_{\mathrm{Cl}} \mathrm{L}_{2}$ is thermally decomposed in the presence of $\mathrm{MCM}-48$, and treated by $\mathrm{H}_{2}$ and subsequently by thermal annealing, a black powder is obtained. The XRD pattern of this Pt $0 \mathrm{MCM}-48$ sample shown in Figure ld exhibits a broad hump around $2 \theta=2.2^{\circ}$, which is decreased significantly as compared to the (211) peak of MCM-48. When $\mathrm{SiO}_{2}$ content of the black powder is removed by $\mathrm{HF}$ treatment, template-free nanostructured $\mathrm{Pt}$ is prepared (Elemental Analysis; $\mathrm{C}, 0.0 \%$ ). TEM image of this material is shown in Figure 3, where the MCM-48-like texture is clearly seen, as suggested by the weak broad hump at $2 \theta=2.2^{\circ}$ in the XRD pattern (Fig. 1e). The XRD pattern of this sample also exhibits broad peaks at $39.8^{\prime \prime}, 46.2^{\circ}$, and $67.5^{\circ}$ corresponding to (111), (200), and (220) reflections, respectively, of face-centered cubic (fcc) $\mathrm{Pt}$ (See the inset of Figure 1e, ICPDS card No: 4-802). Some rather large ( 10 nin) $\mathrm{Pt}$ particles, presumably formed by sintering of $\mathrm{Pt}$ 


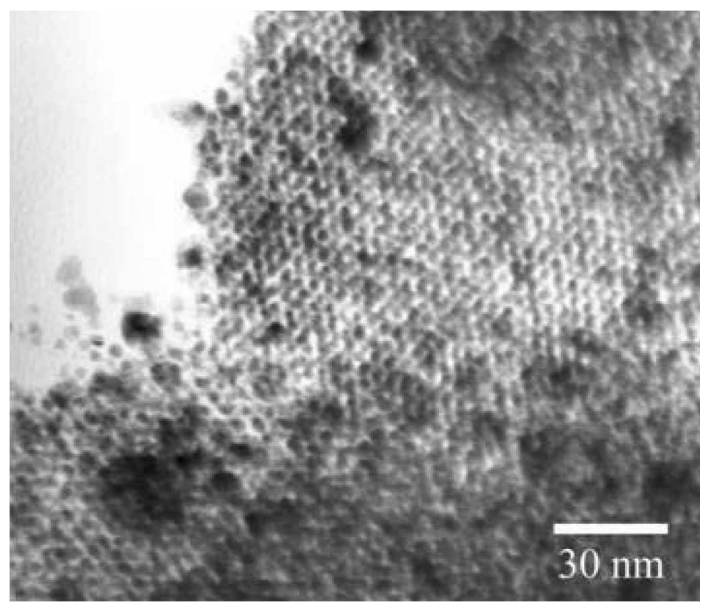

Figure 3. TFM image of template-liee nanostructured l't.

nanoparticles on the outer surface of MCM-48, are also observed on the surlace of the fabric-like Pi nano-network. Their content in the whole sample, however, is marginal, as indicated by the absence of sharp peaks in the XRD pattern.

Very high BET surlace areas of $126 \mathrm{~m}^{2} / \mathrm{g}$ and $93 \mathrm{~m}^{2} / \mathrm{g}$ have been oblained for the nanostructured $\mathrm{Os}$ and $\mathrm{Pl}$, respectively, from $\mathrm{N}_{2}$ adsorption isotherms, suggesting their potential utility as eflicient heterogencous calalysts.

In conclusion, we have utilized the lacile capillary action of MCM-48 template toward molten organometallic precursors to prepare networked metal 3-D nanostructures. The simple experimental procedure and availability of numerous organometallic precursors with similar decomposition behaviors would make this capillarity-based template synthesis a very promising method for the preparation of various functional mesoporous metals.

\section{Experimental Section}

3-D structured $N$-Pt. The mixiure of MCM-48 (0.2 g) and fincly ground $\mathrm{P}(\mathrm{COD}) \mathrm{Cl}_{2}(0.5$ g, Strem Chemicals, $99 \%$ ) in a $50 \mathrm{~mL}$ Pyrex Schlenk tube connected to a bubbler was heated at $250^{\circ} \mathrm{C}$ for $12 \mathrm{~h}$ under $\triangle \mathrm{r}$ atmosphere to give a black powder. Additional $\mathrm{Pt}_{\mathrm{t}}(\mathrm{COD}) \mathrm{Cl} \mathrm{l}_{2}(0.5 \mathrm{~g} ;$ Pt metal content $=0.26 \mathrm{~g}$ ) powder was introduced to the Schlenk tube against $\Lambda \mathrm{r}$ stream and was thermally treated under the same condition. After tratment with $\mathrm{H}_{2}$ al 400 " $\mathrm{C}$ for $6 \mathrm{~h}$ to remove $\mathrm{C}$ and $\mathrm{Cl}$ impurities, themal annealing at $500^{\circ} \mathrm{C}$ under $\mathrm{Ar}$ for $12 \mathrm{~h}$, and $\mathrm{SiO}_{2}$ removal with $48 \%$ IIF in $\mathrm{I}_{2} \mathrm{O}$ (20 molar excess based on Si content), voluminous black powder of nanostructured $\mathrm{P} 1(0.49 \mathrm{~g})$ was obtained.

Characterization of 3-D structured $\mathrm{N}$-Os and $\mathrm{N}$-Pt. The prepared materials were characterized by XRT) (Rigaku
Miniflex (Cu K $x, 0.5 \mathrm{~kW}, \mathrm{RT})$ ) and TEM (Philips CM20 operated at $160 \mathrm{kV}$ ). Samples for TFM investigations were prepared by putting an alicutut of methanol suspension of $\mathrm{N}$ Os and $N$-Pl onto an amorphous carbon substratc supported by copper grid. The BFT surface areas were obtained from nitrogen adsorption dala. Vitrogen adsorption isotherms were measured on a Micromeritics $\triangle$ S $А$ P 2010 Volumetric adsorption analyzer.

Acknowledgments. The authors thank the Korea Research Foundation for the financial support (KRF-2004003-C00116) of this rescarch.

\section{References}

I. (a) Stcigerwald, M. I..: Brus, L. E.. Acc. Chem. Res. 1990, 23, 183. (b) Schmid, G. Chem. Rev: 1992, 92, 1709. (c) Alivisatos, A. P. Science 1996, 27/, 933. (d) Sun, Sin Murray. C. B.; Weller, D.: lolks, l.; Moser, A. Sciestee 2000, 287, 1989.

2. (a) Sehmid, G.; Chi, L. E. Adt. Mater: 1948, J0, 515 (b) Johnson, B. F. G. Coont. (hem. Rev, 1999, 190, 1269. (c) Roucoux, A; Schul7. J.; Patin. II. Chem. Rev. 2002, 102, 3757.

3. Son, S. U.: Jang, Y.; Park, I.; Na. HI. B.: Park, II. W.: Yun. H. I.; Lew, J.; Hycon, T. J. Am Chem. Soc. 2004, /26, 5026.

4. Tamura, M.; Fujiharam, 1I. .J. Am. Chem. Soc: 2003, /25, 15742.

5. Kim, S.-W.; Kim, M.; Lee, W. Y.; Ilycon, T. $J$. Am. Chem. Suc. 2002, 124,7642 .

6. I.cslic-Pelecky', D. I.; Ricke, R. D. Chem. Woter 1996. \&. 1770.

7. (a) Kressec. C. T.: Lconowicz, M. Г.; Roth, W. J.: Vartuli, J. C. Beck, J. S. Notture 1992, 359, 710. (b) Bock. J, S.; Vartuli, J. C. Roth, W. J.; Lconowicz, V. LE.; Kresge, C. T.; Schnitt, K. D.; Chi, C. T.-W.; Olson, D. I.; Sheppard, E. W.: Mecullen, S. B.; Iliggins, J. B.; Schlenker, J. I. J. Am. Chem. Soc. 1992, //4, 10834 .

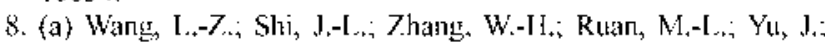
Yan, D,-S. Cheme Mtter: 1999, H, 3015, (b) I Lan, Y,-J.: Kim, J. M.; Stucky, G. D. Chem. Hater: 2000, 12, 2068. (c) Liu, Z.; Sakamoto, Y; Ohsuna. T.; Hliraga, K.; Terasaki, O.; Ko. C. II.; Shin, H. J.: Ryoo, R. Angew. Chem. Int Ed. 2000, 39, 3107. (d) Shin, H. J.; Ryoo, R: liu, 7.: Terasaki, O.J. Am. Chem Soc. $2001,123,1246$.

9. (a) Kang, H.; Jun, Y.-W.: Park, I.-I.; I.ec, K.-B.; Cheon, J. Chem. Mater. 2000, /2, 3530. (b) Lee, K.-B.; Lec, S.-M.; Cheon, l. ditv Mfater. 2001, 13,517 .

10. (a) Wakayama, H.; Fukushima, Y. Chem. Commun. 1999, 391. (b) Coleman, N, R, B.: Morris, M, A, Spalding, T, R.: Holmes, J. D. J. 1m. Chem. Soc, 2001, 123, 187 .

11. I.ce, K,; Kim, Y,-H,; Itan, S, B,; Kang, II,; Park, S,; Sco, W, S.; Pask, I. T.; Kim, B.; Chang, S. J. Am. Chem. Soc 2003, /25, 6844.

12. Ryoo, R.: Joo, S. H.; Kim, J. M. J. Phrs. Chem. B 1999, 103, 7435 .

13. Fady, C. R.; Johnson, B. Г. G.; Lewis, J; Matheson, T. I. Organomet. Chem. 1973, 57, C82.

14. Matler, B.: Obeshagemann. U.; Vonmann, S.; Gies, H. Mficroporous Wher: $1996,6,375$.

15. Ryoo, R.; Joo, S. I1.: Jun, S. J. Phis. Chem. B 1999, $/ 03,7743$. 